\title{
A rare case of anastomosis between the external and internal jugular veins
}

\author{
This article was published in the following Dove Press journal: \\ International Medical Case Reports Journal \\ 21 March 2016 \\ Number of times this article has been viewed
}

\section{Ilias Karapantzos' \\ Paul Zarogoulidis ${ }^{2}$ \\ Charalampos Charalampidis ${ }^{3}$ \\ Chrysanthi Karapantzou' \\ loannis Kioumis ${ }^{2}$ \\ Kosmas Tsakiridis ${ }^{4}$ \\ Andrew Mpakas ${ }^{4}$ \\ Nikolaos Sachpekidis ${ }^{4}$ \\ John Organtzis ${ }^{2}$ \\ Konstantinos Porpodis ${ }^{2}$ \\ Konstantinos Zarogoulidis ${ }^{2}$ \\ Georgia Pitsiou ${ }^{2}$ \\ Athanasios Zissimopoulos ${ }^{5}$ \\ Christoforos Kosmidis ${ }^{6}$ \\ Evagelia Fouka ${ }^{2}$ \\ Theodoros Demetriou ${ }^{3}$ \\ 'Ear, Nose and Throat Department, \\ "Saint Luke" Private Hospital, \\ Panorama, ${ }^{2}$ Pulmonary Department, \\ "G. Papanikolaou" General Hospital, \\ Aristotle University of Thessaloniki, \\ Thessaloniki, ${ }^{3}$ Department of \\ Anatomy, Democritus University \\ of Thrace, Alexandroupolis, \\ ${ }^{4}$ Cardiothoracic Surgery Department, \\ "Saint Luke" Private Hospital, \\ Panorama, Thessaloniki, ${ }^{5}$ Nuclear \\ Medicine Department, University \\ General Hospital of Alexandroupolis, \\ Democritus University of Thrace, \\ Alexandroupolis, 'Surgery \\ Department, "Interbalkan" European \\ Medical Center, Thessaloniki, Greece}

Correspondence: Paul Zarogoulidis

Pulmonary Department-Oncology Unit,

"G. Papanikolaou" General Hospital,

Aristotle University of Thessaloniki,

Thessaloniki 54I24, Greece

Fax +30 23I 0992424

Email pzarog@hotmail.com

\begin{abstract}
Jugular veins bring deoxygenated blood from the head back to the heart. There are two sets of external and internal veins. The external jugular vein receives the greater part of the blood from the cranium and the deep parts of the face. It commences from the substance of the parotid gland and runs down the neck at the posterior border of sternocleidomastoideus and ends in the subclavian vein in front of the scalenus anterior. The external jugular vein is covered by the platysma and its upper half runs parallel with the great auricular nerve. There is also another minor jugular vein, the anterior, draining the submaxillary region. In our patient, we recognized a shunt between the external and internal jugular veins. It appeared in the middle of the veins, between the pair of valves, which are placed $\sim 2.5 \mathrm{~cm}$ above the termination of the vessel. The anastomosis was fully functional, and there was no problem in the blood pressure of the patient. Moreover, the shunt was not associated with any systemic disease.
\end{abstract}

Keywords: jugular veins, anastomosis, parotid gland

\section{Introduction}

Jugular veins bring deoxygenated blood from the head back to the heart. There are two sets of external and internal veins. The external jugular vein (EJV) receives the greater part of the blood from the exterior of the cranium and the deep parts of the face. It commences in the substance of the parotid gland and runs down the neck at the posterior border of sternocleidomastoideus. It ends in the subclavian vein in front of the scalenus anterior. It is covered by the platysma and its upper half runs parallel with the great auricular nerve. There is also another minor jugular vein, the anterior, draining the submaxillary region. The internal jugular vein (IJV) is a paired vein collecting the blood from the brain, neck, and the superficial parts of the face. At the base of the brain, the inferior petrosal sinus and the sigmoid sinus join to form the IJV. It begins in the posterior compartment of the jugular foramen. It runs down the side of the neck in a vertical direction and is united with the subclavian vein to form the brachiocephalic vein. It is a little distance from the common carotid artery. The left vein is smaller than the right and each contains a pair of valves, which are placed $\sim 2.5 \mathrm{~cm}$ above the termination of the vessel. Parts of the right sternocleidomastoid and platysma have been excised to expose the trunk of the IJV. The EJV is visible through the lower part of the platysma. Near its end, a large branch often descends along the anterior border of sternocleidomastoid to the anterior jugular vein. Its uppermost segment, above its junction with the superior labial vein (vide infra) is often termed as angular vein. Near its beginning, the facial vein connects with the superior ophthalmic vein both directly 
and via the supraorbital vein; it is thus connected to the cavernous sinus. It receives veins of the ala nasi and, lower, a large deep facial vein from the pterygoid venous plexus. Below the omohyoid, it is covered by the infrahyoid muscles and the sternocleidomastoid muscles and it is crossed by the anterior jugular vein. Deep cervical lymph nodes lie along the vein, mainly on its superficial aspect. At the root of the neck the right IJV is separated from the common carotid, but the left usually overlaps its artery. At the base of the skull the internal carotid artery is anterior, separated from the vein by the ninth to 12 th cranial nerves. ${ }^{1-4}$

\section{Surface anatomy}

The IJV is represented in surface projection by a broad band from the ear lobule to the medial end of the clavicle; its inferior bulb is in the interval (depression) between the sternal and clavicular heads of the sternocleidomastoid (ie, the bulb bulges into the lesser supraclavicular fossa; a needle may be inserted here with precision).

Tirbutaries are the inferior petrosal sinus, facial, lingual, pharyngeal, superior, and middle thyroid veins, and sometimes the occipital. They may communicate with the EJV. The thoracic duct opens near the union of the left subclavian and IJVs; the right lymphatic duct is at the same site on the right.

\section{Case report}

During root cervical cleaning of a 54-year-old male suffering from supraglottic cancer, we observed a combination of the right EJV with the IJV at the level of the thyroid cartilage. The merger took place through a medium-sized vein, which passes above the thyroid cartilage without folds or other processes. The vein has a length of $\sim 1.5 \mathrm{~m}$. It starts moving from the right EJV, approximately in the middle thereof, and passing through the sternocleidomastoid muscle leads downwardly via the jugular vein. The vein was operated as

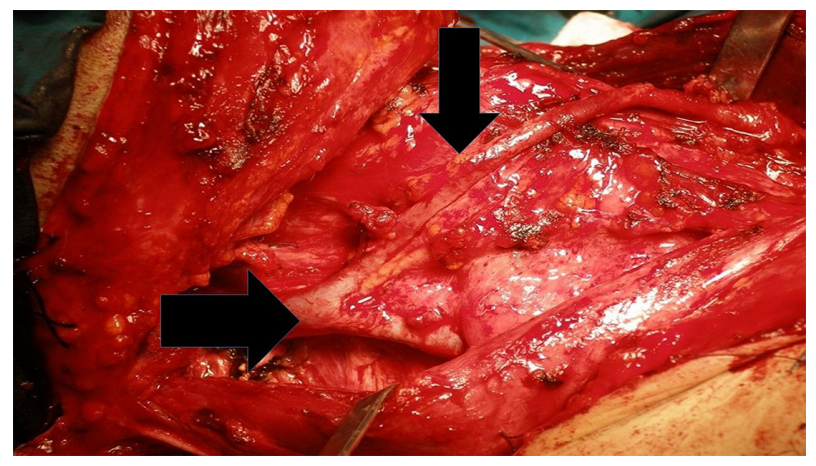

Figure I Anatomic findings during surgery.

Notes: Left arrow indicates right jugular vein, while right arrow indicates the variation of this vessel.

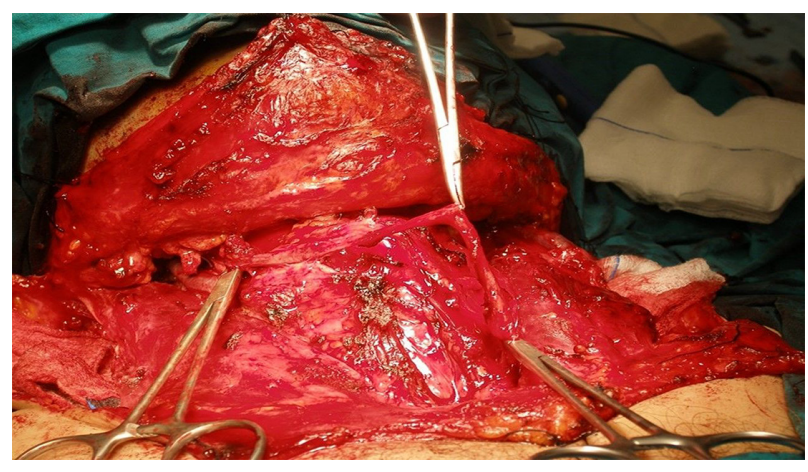

Figure 2 The ligation of the vessel.

an extra EJV and drained the blood normally to the IJV. This whole complex is approximately 7.5 million to 1 (Figures 1 and 2). ${ }^{1-4}$ This case report presentation was approved by the investigational review board of "G. Papanikolaou” General Hospital. Written informed consent was obtained from the patient, in order to proceed with the publication.

\section{Discussion}

The rarity of this incident was confirmed by the literature. Similar incidents are poorly recorded. This study has clinical value, not only for anatomists and clinicians performing invasive procedures in the region but also for radiologists applying invasive techniques. In addition, a proper study of the headneck area will help future anatomists to better understand the topography and any variants. Yadav et al reported a case where EJV crossed sternocleidomastoid superficially and ended in IJV. ${ }^{1}$ Choudhry et al reported a case of anterior facial vein ending as EJV. ${ }^{2}$ This vein develops from the cephalic vein and anastomoses secondarily with the anterior facial vein. In our case, we recognized a shunt between the EJV and IJV. It appeared in the middle of the veins, between the pair of valves, which are placed $\sim 2.5 \mathrm{~cm}$ above the termination of the vessel. The anastomosis was fully functional, with no problem in the blood pressure of the patient, and was not associated with any systemic disease. . $^{3,4}$

\section{Disclosure}

The authors report no conflicts of interest in this work.

\section{References}

1. Yadav S, Ghosh SK, Anand C. Variations of superficial veins of head and neck. J Anat Soc India. 2000;49:61-62.

2. Choudhry R, Tuli A, Choudhry S. Facial vein terminating in the external jugular vein. An embryologic interpretation. Surg Radiol Anat. 1997;19:73-77.

3. Hollinshead WH. Anatomy for Surgeons. The Head and Neck. Harper and Row, New York, NY, USA; 1998:530.

4. Siegel EL, Caresio J, Eckard DA. Use of the external jugular vein approach for tranasvenous liver biopsy. J Vasc Interv Radiol. 1992;3:371-374. 
International Medical Case Reports Journal

Dovepress

\section{Publish your work in this journal}

The International Medical Case Reports Journal is an international, peer-reviewed open-access journal publishing original case reports from all medical specialties. Previously unpublished medical posters are also accepted relating to any area of clinical or preclinical science. Submissions should not normally exceed 2,000 words or

4 published pages including figures, diagrams and references. The manuscript management system is completely online and includes a very quick and fair peer-review system, which is all easy to use. Visit $\mathrm{http}: / / \mathrm{www}$.dovepress.com/testimonials.php to read real quotes from published authors.

Submit your manuscript here: http://www.dovepress.com/international-medical-case-reports-journal-journal 